\title{
Co-culture of Saccharomyces cerevisiae (VS3) and Pichia stipitis (NCIM 3498) for bioethanol production using concentrated Prosopis juliflora acid hydrolysate
}

\author{
Shaik Naseeruddin ${ }^{1,2}$, Suseelendra Desai ${ }^{2 *}$ and L Venkateswar Rao ${ }^{1}$ \\ ${ }^{1}$ Department of Microbiology Osmania University, ${ }^{2}$ Central Research Institute for Dry land \\ Agriculture \\ *Corresponding author, email: desai1959@yahoo.com
}

\begin{abstract}
Bioethanol production from lignocellulosic biomass is a viable option for improving energy security and reducing green house emissions. In the present study Prosopis juliflora, an invasive tree found through out India, with total carbohydrate content of $67.4+/-6 \%$ was selected as lignocellulosic feedstock for bioethanol production. The hydrolysate obtained after biphasic dilute acid hydrolysis contained initial sugar concentration of $18.70+/-0.16 \mathrm{~g} / \mathrm{L}$ and hence to increase the ethanol yield it was concentrated to $33.59+/-0.52 \mathrm{~g} / \mathrm{L}$ (about two-folds) by vacuum distillation. The concentration of sugars, phenols and furans was analyzed before and after concentration process. The concentrated hydrolysate was further detoxified by over liming, neutralization and charcoal treatment and later used for ethanol fermentation by mono- and co culture method. Monoculture of Saccharomyces cerevisiae (VS3) and Pichia stipitis (NCIM 3498 ) produced $8.52+/-0.43$ and $4.52+/-0.23 \mathrm{~g} / \mathrm{L}$ of ethanol with $66.21+/-3.26 \%$ and 60.46 $+/-3.02 \%$ of fermentation efficiency, $0.33+/-0.02$ and $0.31+/-0.02 \mathrm{~g} / \mathrm{g}$ of ethanol yield and $0.24+/-0.01$ and $0.13+/-0.01 \mathrm{~g} / \mathrm{L} / \mathrm{h}$ of productivity, respectively. The co-culture of $S$. cerevisiae (VS3) and P. stipitis (NCIM 3498) helped to improve all parameters i.e. 10.94 +/$0.53 \mathrm{~g} / \mathrm{L}$ of ethanol with fermentation efficiency, ethanol yield and productivity of $83.11+/-$ $0.42 \%, 0.420+/-0.01 \mathrm{~g} / \mathrm{g}$ and $0.30+/-0.01 \mathrm{~g} / \mathrm{L} / \mathrm{h}$, respectively.
\end{abstract}

Key words: Biofuel, Lignocellulosic substrate, Prosopis juliflora, Concentration, Detoxification, Monoculture, Co-culture, Bioethanol. 


\section{Introduction}

Lignocellulosic substrates are in great abundance, easily available, relatively low-cost and have potentiality to produce clean fuel when compared to sugar or starch containing feedstocks (Naseeruddin et al., 2013; Romani, Garrote, Ballesteros, \& Ballesteros, 2013). Hence, exploitation of these sources may provide sustainable energy supply at local, regional and national level and thereby improving the economy of the nation (Balat \& Balat, 2009) without hampering food security. Moreover, bioethanol has got the adaptability to existing engines and if used in transportation can replace 30\% of gasoline use (Krishnan et al., 2010; Oleskowicz, Thomsen, Schmidt, 2011).

Prosopis juliflora is a perennial deciduous thorny shrub, commonly growing in semi-arid region of Indian subcontinent, Saudi Arabia and the United States of America (Gupta, Sharma \& Kuhad, 2009). It is an invasive species and considered as threat to the ecosystem affecting adversely the biodiversity of the region. However, the tree is valued for the shade, forage and can tolerate drought, salinity as well as grazing (Pasha, Thabit, Kuhad, \& Linga, 2008). To eradicate this tree species mechanical, chemical and biological control programmes are commonly employed but there are other options available to utilize positively for human welfare (Rilov \& Crooks, 2009). The viable options to manage the menace of these invasive plants for human welfare include its use as fuel wood and application in biofuel industry (Rilov \& Crooks, 2009) as its carbohydrate content is $69.25 \%$ (on dry weight basis). As the tree does not form a part of main food or feed cycle, it qualifies to be a suitable substrate for long-term sustainable production of bioethanol (Pasha, Thabit, Kuhad, \& Linga, 2008).

It is recommended that prior to distillation the fermented broth should contain higher concentration of ethanol which makes it imperative that initial sugars in the hydrolysate should be high. Concentration of initial sugars in the water soluble fraction of hydrolysate can be achieved by evaporation of water or addition of less water to the hydrolysis process or concentrating the hydrolysate at $70^{\circ} \mathrm{C}$ under vacuum (Srilekha Yadav, Naseeruddin, Sai Prashanthi, Sateesh \& Venkateswar Rao, 2011). Carvalho, Mussatto, Cândido, \& Almeida e 
Silva, (2006) concentrated the acid hydrolysate of Eucalyptus shavings and reported proportional increase in the sugar content as a function of the concentration factor employed.

The hydrolysate obtained after acid saccharification of lignocellulosic biomass contains toxic compounds generated mainly due to the degradation of sugars from hemicellulose and cellulose. These inhibitors interfere with the physiology of yeast cells resulting in decreased cell viability, ethanol yield and productivity (Chandel, Kapoor, Singh \& Kuhad, 2007; Hahn-Hagerdal, Karhumaa, Fonseca, Spencer-Martins, \& Gorwa-Grauslund, 2007). To minimize the effect of these inhibitory compounds several detoxification methods have been studied, but the effectiveness of each method depends on the type of hydrolysate and microorganism used (Anish \& Rao, 2009). Moreover, each detoxification method has specificity for certain compounds; therefore combining one or more methods can yield better results for detoxification of the acid hydrolysate (Carvalho, Mussatto, Cândido, \& Almeida e Silva, 2006). Overliming followed by neutralization and charcoal treatment method is most widely used and is considered as a promising and economic method of detoxification (Pasha, Thabit, Kuhad, \& Linga, 2008; Junjun, Qiang, Yong \& Shi-Yuan, 2009; Chandel, da Silva \& Singh, 2011a).

Choice of organism is important in ethanol production from lignocellulosic materials as the hydrolysate contains mixture of both hexoses and pentoses like dextrose, galactose, mannose, xylose and arabinose. For economical production of lignocellulose-based ethanol, simultaneous utilization of these biomass-derived sugars is required (Lin and Tanaka, 2006). Although many organisms are available, most of the microorganisms lack efficiency to ferment both hexose and pentose sugars present in the hydrolysate. Though, Saccharomyces cerevisiae and Zymomonas mobilis are most commonly used microorganisms for ethanol production, they lack the ability to utilize pentose sugars (Hector et al., 2011). S. cerevisiae is mostly used in industrial processes for ethanol production because of several advantages such as high ethanol productivity, high tolerant of high ethanol concentrations and inhibitors associated with it (Hickert, da CunhaPereira, de Souza-Cruz, Rosa, \& Ayub, 2013). Other yeasts like P. stipitis, Candida shehatae and Pachysolen tannophilus have also attracted interest as choice of organisms as they can convert pentose sugars into ethanol but are less tolerant of ethanol and inhibitors and also require a small and well-controlled supply of oxygen for maximum ethanol production (Hickert, da Cunha-Pereira, de Souza-Cruz, Rosa, \& Ayub, 2013). Despite many attempts, the microbial strains improved by genetic engineering or protoplast fusion showed preference for one sugar 
over another as a result of catabolite repression leading to longer time for the complete utilization and fermentation of all the sugars. Therefore, co-culture fermentation for the fermentation of mixture of sugars is a viable option (Srilekha Yadav, Naseeruddin, Sai Prashanthi, Sateesh, \& Venkateswar Rao, 2011) which circumvents the problems associated with monoculture of the wild strains or engineered yeast strains (Hickert, da Cunha-Pereira, de Souza-Cruz, Rosa, \& Ayub, 2013). Therefore, in the present study an attempt has been made to utilize concentrated hydrolysate of $P$. juliflora pre-treated with dilute acid where both the sugars can simultaneously get fermented to ethanol by co-culturing with $S$. cerevisiae (VS3) and $P$. stipitis (NCIM 3498).

\section{Materials and Methods}

\subsection{Microorganisms}

2.1.1 Saccharomyces cerevisiae VS3: is an isolate of our laboratory that originated from the soil samples collected within the hot regions Thermal Power Plant, Kothagudem India (Kiran Sree, Sridhar, Suresh, Banat, \& Venkateswar Rao, 2000). It was maintained on yeast extract, peptone, dextrose and agar (YEPDA) containing 10, 20, 20 and $25 \mathrm{~g} / \mathrm{L}$, respectively. The $\mathrm{pH}$ of the medium was adjusted to $5.5 \pm 0.2$.

2.1.2 Pichia stipitis (NCIM 3498) was obtained from National Collection of Industrial Microorganism (NCIM), National Chemical Laboratory, Pune, India and was maintained on media containing Malt extract (5 g/L), Glucose $(5 \mathrm{~g} / \mathrm{L})$, Xylose $(30 \mathrm{~g} / \mathrm{L})$, Yeast extract $(5 \mathrm{~g} / \mathrm{L})$, Peptone $(20 \mathrm{~g} / \mathrm{L})$ and agar-agar $(25 \mathrm{~g} / \mathrm{L})$. The $\mathrm{pH}$ of the medium was adjusted to $5.5 \pm 0.2$.

\subsection{Concentration of hydrolysate to increase sugar concentration}

Acid hydrolysate $(1845 \mathrm{ml})$ obtained at $100 \mathrm{~g}$ level of substrate as reported earlier Shaik Naseeruddin, Suseelendra Desai and L Venkateswar Rao, 2017 was concentrated to increase the sugar concentration for ethanol fermentation by vacuum distillation (assembled in the lab). During the vacuum distillation, the boiling temperature of the liquid was maintained at $70^{\circ} \mathrm{C}$ as per Dehkhoda \& Brandberg, (2008). Sugars, phenolics and furans were checked before and after the concentration process. 


\subsection{Detoxification of concentrated acid hydrolysate}

The concentrated hydrolysate was detoxified by overliming with $\mathrm{CaO}$, followed by $\mathrm{pH}$ adjustment to $6.00 \pm 0.5$ using $6 \mathrm{~N} \mathrm{H}_{2} \mathrm{SO}_{4}$ and treated with charcoal. Sugars, phenolics and furans were estimated before and at each step of detoxification process. The acid hydrolysate was first detoxified by $\mathrm{CaO}$ addition at room temperature till the $\mathrm{pH}$ reached $10.5 \pm 0.5$ under fast stirring. The mixture was incubated for $1 \mathrm{~h}$ with intermittent stirring to precipitate the inhibitors. The slurry was then filtered under vacuum to get clear filtrate by removing precipitates as described by Chandel, Kapoor, Singh \& Kuhad, 2007. The pH of the clear filtrate obtained after treating the hydrolysate with $\mathrm{CaO}$ was adjusted to $6.00 \pm 0.5$ by using $6 \mathrm{~N} \mathrm{H}_{2} \mathrm{SO} 4$ and again filtered under vaccum to remove traces of salt precipitates as described by Chandel, Kapoor, Singh \& Kuhad, 2007. After overliming and neutralization the hydrolysate was treated with $3.5 \%(\mathrm{w} / \mathrm{v})$ of activated charcoal and stirred for $1 \mathrm{~h}$ as described by Martinez, Rodriguez, York, Preston, Ingram, (2000). The mixture was centrifuged at $3000 \mathrm{rpm}$ for $20 \mathrm{~min}$ followed by filtration under vacuum to remove traces of precipitates.

\subsection{Fermentation of pentoses and hexoses by mono- and co-culture}

Concentrated hydrolysate was used as substrate for fermentation studies by performing monoand co-culture studies. The organisms utilized for the studies were hexose utilizing strain viz Saccharomyces cerevisiae (VS3) and pentose utilizing strain Pichia stiptis (NCIM 3498) (Srilekha Yadav, Naseeruddin, Sai Prashanthi, Sateesh, \& Venkateswar Rao, 2011).

\subsubsection{Inoculum preparation}

Thermotolerant yeast Saccharomyces cerevisiae (VS3) inoculum was prepared by growing the microorganism on YEPD medium consisting of $(\mathrm{g} / \mathrm{L})$ : yeast extract, 10; peptone, 20; dextrose, 20; pH: $5.5 \pm 0.2$ for $48 \mathrm{~h}$ at $37 \pm 0.5^{\circ} \mathrm{C}$ and $100 \mathrm{rpm}$ in Erlenmeyer flasks on a rotary shaker (Pasha, Kuhad, \& Linga, 2007). This $48 \mathrm{~h}$ inoculum with an O.D of $0.6(10 \%, \mathrm{v} / \mathrm{v})$ at $600 \mathrm{~nm}$ prepared in $50 \mathrm{ml}$ YEPD broth was transferred to fermentation medium (Gupta, Sharma \& Kuhad, 2009; Chandel, Kapoor, Singh \& Kuhad, 2007) 
Inoculum of Pichia stipitis (NCIM 3498) was prepared by growing it aerobically in Erlenmeyer flasks on a rotary shaker in medium consisting of $(\mathrm{g} / \mathrm{L})$ : Xylose - 5; dextrose - 5; yeast extract 5; malt extract -5; peptone - 5; pH $5.5 \pm 0.2$ for $24 \mathrm{~h}$ at $30{ }^{\circ} \mathrm{C}$ and $100 \mathrm{rpm}$. This $24 \mathrm{~h}$ old inoculum with an O.D. of $0.6(10 \%, \mathrm{v} / \mathrm{v})$ at $600 \mathrm{~nm}$ was transferred to fermentation medium (Gupta, Sharma \& Kuhad, 2009; Pasha, Kuhad, \& Linga, 2007).

\subsubsection{Fermentation medium}

The concentrated and detoxified acid hydrolysate was used for fermentation. Reducing sugars present in the hydrolysate were used as source of carbon hence no other external carbon source was added to the hydrolysates. The hydrolysate was supplemented with $0.1 \%(\mathrm{w} / \mathrm{v})$ each of yeast extract, peptone, $\mathrm{NH}_{4} \mathrm{Cl}, \mathrm{KH}_{2} \mathrm{PO}_{4}$; and $0.05 \%$ (w/v) each of $\mathrm{MgSO}_{4} .7 \mathrm{H}_{2} \mathrm{O}, \mathrm{MnSO}_{4} .5 \mathrm{H}_{2} \mathrm{O}$, $\mathrm{CaCl}_{2} \cdot 2 \mathrm{H}_{2} \mathrm{O}, \mathrm{FeCl}_{3} \cdot 2 \mathrm{H}_{2} \mathrm{O}$ and $\mathrm{ZnSO}_{4} .7 \mathrm{H}_{2} \mathrm{O}$ before fermentation. The $\mathrm{pH}$ of medium was adjusted to $5.5 \pm 0.1$ and autoclaved at $110^{\circ} \mathrm{C}$ for $20 \mathrm{~min}$ (Pasha, Kuhad, \& Linga, 2007), cooled to $30 \pm 2^{\circ} \mathrm{C}$ and used for fermentation.

\subsubsection{Ethanol production by monoculture with hydrolysate at $100 \mathrm{~g}$ level}

Monoculture studies with Saccharomyces cerevisiae (VS3) and Pichia stiptis (NCIM 3498) were carried out separately in individual flasks using detoxified and concentrated acid hydrolysate obtained at $100 \mathrm{~g}$ level of substrate. At first, $600 \mathrm{ml}$ of detoxified concentrated hydrolysate was supplemented with nutrients. A $30 \mathrm{ml}$ of hydrolysate was taken from $600 \mathrm{ml}$ of hydrolysate in three different flasks for fermentation. The $\mathrm{pH}$ of the hydrolysate was adjusted to $5.5 \pm 0.1$ and autoclaved, inoculated with $10 \%(\mathrm{v} / \mathrm{v})$ inoculum of each organism separately. The shake flask fermentation was carried out at $30 \pm 2^{\circ} \mathrm{C}, 150 \mathrm{rpm}$ for $72 \mathrm{~h}$ and samples were collected at regular intervals to estimate residual sugar and ethanol concentration.

\subsubsection{Ethanol production by co-culture with hydrolysate at $100 \mathrm{~g}$ level of substrate}

About $150 \mathrm{ml}$ of hydrolysate was taken from $600 \mathrm{ml}$ of detoxified and concentrated acid hydrolysate obtained at $100 \mathrm{~g}$ level of substrate and supplemented with nutrients. The $\mathrm{pH}$ of medium was adjusted to 5.5 \pm 0.1 , autoclaved (Pasha, Kuhad, \& Linga, 2007) and inoculated with co culture of Pichia stipitis (NCIM 3455) + Saccharomyces cerevisiae (VS3) (added one after the other with an interval of $18 \mathrm{~h}$ ). The flasks were incubated on a shaker; samples were 
collected at regular intervals, centrifuged at $6000 \mathrm{rpm}$ for $10 \mathrm{~min}$ at $4^{\circ} \mathrm{C}$ and analyzed for residual sugars and ethanol.

\subsection{Analytical Methods}

The total reducing sugars released during delignification and after acid hydrolysis were estimated by DNS method (Miller, 1959). The fermentation inhibitors viz. furans and phenolics were analyzed spectroscopy. Phenolics were estimated by Folin - Ciocalteus method (Singleton and Rossi, 1965), and furans by Martinez, Rodriguez, York, Preston, Ingram, (2000). For estimation of phenolics, to the test tube containing $0.1 \mathrm{ml}$ of sample mixed with $8.4 \mathrm{ml}$ of distilled water, $0.5 \mathrm{ml}$ of Folin-Ciocalteus reagent was added. Later after $5 \mathrm{~min}, 1 \mathrm{ml}$ of $10 \%$ sodium carbonate was added. A blank without sample served as control. The reaction mixture was incubated at room temperature for $1 \mathrm{~h}$ and read at $750 \mathrm{~nm}$ against blank with gallic acid as standard. For estimation of furans, the hydrolysate obtained was neutralized and read at $284 \mathrm{~nm}$ and $320 \mathrm{~nm}$ against water as blank. The furan concentration at $320 \mathrm{~nm}$ was subtracted from the concentration at $284 \mathrm{~nm}$ and a correction factor of 0.056 was added to the final value. Fufuraldehyde was used as standard for total furans estimation. Cell density was measured turbidometrically at $600 \mathrm{~nm}$. Fermentation broth was diluted 10 times using sterile water and turbidity was measured with a UV-VIS spectrophotometer 117 (Systronics India).

Ethanol produced was analyzed by gas chromatography (Shimadzu GC-2011- Japan) using ZBWax column (30 $\mathrm{mm} \times 0.25 \mathrm{~mm}$ ) with a flame ionization detector. The analysis was performed according to National Renewable Energy Laboratory procedure LAP \#001 (David, 1994). The column temperature was maintained at $150^{\circ} \mathrm{C}$ (isothermal) and the carrier gas nitrogen was run at pressure of $16 \mathrm{kPa}$ with a run time of $5.5 \mathrm{~min}$ as ethanol has retention time of about $2.3 \mathrm{~min}$. The injector temperature was at $175^{\circ} \mathrm{C}$ and the detector temperature was at $250^{\circ} \mathrm{C}$. The other parameters used were flow rate: $40 \mathrm{ml} / \mathrm{min}$, spilt ratio: 1/50, velocity of $\mathrm{H}_{2}$ flow: $60 \mathrm{ml} / \mathrm{min}$, sample quantity: $1 \mu 1$. The sample used for ethanol estimation was filtered by $0.22 \mu \mathrm{m}$ cellulose acetate filter for GC analysis.

\subsection{Statistical Analysis}


All the experiments were conducted in triplicate and mean and standard deviation (SD) values were calculated using MS Excel software. Anova was carried out by using SPSS statistical package software version 19.0.

\section{Results}

\subsection{Concentration of acid hydrolysate}

Acid hydrolysate obtained at $100 \mathrm{~g}$ level of substrate was concentrated to increase the sugar concentration by vacuum distillation. After concentration, the sugar concentration reached to $33.59 \pm 0.52 \mathrm{~g} / \mathrm{L}$ from initial level of $18.70 \pm 0.16 \mathrm{~g} / \mathrm{L}$, representing about two-fold increase. The main aim of vacuum distillation of acid hydrolysate was to increase the concentration of sugars but phenolics content also got nearly doubled and reached $3.94 \pm 0.18 \mathrm{~g} / \mathrm{L}$ from initial concentration of $2.16 \pm 0.10 \mathrm{~g} / \mathrm{L}$. The furans concentration increased to $1.72 \pm 0.12 \mathrm{~g} / \mathrm{L}$ from initial level of $1.10 \pm 0.03 \mathrm{~g} / \mathrm{L}$ with overall decrease in total volume of hydrolysate from $1845 \mathrm{ml}$ to 922 $\mathrm{ml}$. Concentrated hydrolysate obtained $(922 \mathrm{ml})$ was detoxified by overliming, neutralization with sulphuric acid followed by charcoal addition. By this treatment, there was a reduction of $4.73 \%$ in sugar concentration i.e. from $33.59 \pm 0.52 \mathrm{~g} / \mathrm{L}$ to $32.00 \pm 0.48 \mathrm{~g} / \mathrm{L}$, however, with significant decrease in phenolics content from $3.94 \pm 0.18 \mathrm{~g} / \mathrm{L}$ to $0.558 \pm 0.11 \mathrm{~g} / \mathrm{L}(85.83 \%$ decrease) and furans content from $1.72 \pm 0.12 \mathrm{~g} / \mathrm{L}$ to $0.21 \pm 0.08 \mathrm{~g} / \mathrm{L}(97.79 \%$ reduction) with total final volume decreasing to $600 \mathrm{ml}$ (Table 1) at $\mathrm{p}<0.05 \mathrm{~F}(2,6)=1143.038,472.644$ and 238.935 for sugars, phenolics and furans respectively .

\subsection{Ethanol production by monoculture with acid hydrolysate at $100 \mathrm{~g}$ level of substrate}

A $60 \mathrm{ml}$ of hydrolysate containing a sugar concentration of $32 \pm 0.48 \mathrm{~g} / \mathrm{L}$ was taken from $600 \mathrm{ml}$ of concentrated and detoxified acid hydrolysate obtained at $100 \mathrm{~g}$ level of substrate and distributed equally $(30 \mathrm{ml})$ into two $100 \mathrm{ml}$ Erlenmeyer flasks. The hydrolysate in each flask was supplemented with nutrients and inoculated with 10\% (v/v) Saccharomyces cerevisiae (VS3), and Pichia stipitis (NCIM 3498) separately. Saccharomyces cerevisiae (VS3) produced ethanol of $8.52 \pm 0.43 \mathrm{~g} / \mathrm{L}$ by consuming $25.62 \pm 1.28 \mathrm{~g} / \mathrm{L}$ of sugars from initial sugar concentration of 32 $\pm 0.48 \mathrm{~g} / \mathrm{L}$ with fermentation efficiency, ethanol yield and productivity of $66.21 \pm 3.26 \%$, $0.33 \pm 0.02 \mathrm{~g} / \mathrm{g}$ and $0.24 \pm 0.01 \mathrm{~g} / \mathrm{L} / \mathrm{h}$, respectively, (Fig 1). The pentose sugar fermenting yeast Pichia stipitis (NCIM 3498) produced $4.52 \pm 0.23 \mathrm{~g} / \mathrm{L}$ of ethanol by consuming $14.66 \pm 0.87 \mathrm{~g} / \mathrm{L}$ 
of sugars with fermentation efficiency, ethanol yield and productivity of $60.46 \pm 3.02 \%$, $0.31 \pm 0.02 \mathrm{~g} / \mathrm{g}$ and $0.13 \pm 0.01 \mathrm{~g} / \mathrm{L} / \mathrm{h}$, respectively, (Fig 1).

\subsection{Ethanol production by co culture with acid hydrolysate at $100 \mathrm{~g}$ level of substrate}

In co-culture with concentrated and detoxified acid hydrolysate $(150 \mathrm{ml})$ obtained at $100 \mathrm{~g}$ level of substrate containing a sugar concentration of $32 \pm 0.48 \mathrm{~g} / \mathrm{L}$ as substrate, addition of Saccharomyces cerevisiae (VS3) after $18 \mathrm{~h}$ of addition of Pichia stipitis (NCIM 3498) utilized $25.81 \pm 0.24 \mathrm{~g} / \mathrm{L}$ of sugars and produced $10.94 \pm 0.53 \mathrm{~g} / \mathrm{L}$ of ethanol with fermentation efficiency, ethanol yield and productivity of $83.11 \pm 0.42 \%, 0.420 \pm 0.01 \mathrm{~g} / \mathrm{g}$ and $0.30 \pm 0.01 \mathrm{~g} / \mathrm{L} / \mathrm{h}$, respectively (Fig. 2).

\section{Discussion}

Srilekha Yadav, Naseeruddin, Sai Prashanthi, Sateesh, \& Venkateswar Rao, (2011) reported that batch fermentation of concentrated and detoxified acid hydrolysate of rice straw using coculture of Saccharomyces cerevisiae (OVB 11) and Pichia stipitis (NCIM 3498) resulted in maximum ethanol production after $36 \mathrm{~h}$ of incubation $(12 \mathrm{~g} / \mathrm{L})$ with an efficiency of $95 \%$. The volumetric ethanol productivity was $0.33 \mathrm{~g} / \mathrm{L} / \mathrm{h}$ with a yield of $0.4 \mathrm{~g} / \mathrm{g}$. In the present study also, $10.94 \pm 0.53 \mathrm{~g} / \mathrm{L}$ of ethanol with fermentation efficiency, ethanol yield and productivity of $83.11 \pm 0.42 \%, 0.420 \pm 0.01 \mathrm{~g} / \mathrm{g}$ and $0.30 \pm 0.01 \mathrm{~g} / \mathrm{L} / \mathrm{h}$, respectively, was obtained. The increased ethanol yield and ethanol efficiency is due to the total conversion of both sugars i.e. dextrose and xylose. Chandel, Singh, Narasu \& Rao, (2011b) performed the fermentation of hemicellulose acid hydrolysate with co-culture using Pichia stipitis (NCIM 3498) and thermotolerant yeast Saccharomyces cerevisiae (VS3) and reported $15.0 \pm 0.92 \mathrm{~g} / \mathrm{L}$ of ethanol production with ethanol yield of $0.48 \pm 0.032 \mathrm{~g} / \mathrm{g}$ and volumetric ethanol productivity of $0.208 \pm 0.0142 \mathrm{~g} / \mathrm{L} / \mathrm{h}$. The findings of Sornvoraweat, Buddhiporn, Jirasak \& Kongkiattikajorn, (2009) also support the present study who reported that ethanol yield was maximum from acid hydrolysate of cassava peels when cocultured with Saccharomyces cerevisiae and Candida tropicalis in comparison to monoculture of Saccharomyces cerevisiae.

\section{Conclusions}


The present study was carried out by utilizing concentrated Prosopis juliflora acid hydrolysate to ferment both the sugars simultaneously into ethanol by co-culturing of Saccharomyces cerevisiae (VS3) and Pichia stipitis (NCIM 3498) and able to produce $10.94 \pm 0.53 \mathrm{~g} / \mathrm{L}$ of ethanol with ethanol yield of $0.420 \pm 0.01 \mathrm{~g} / \mathrm{g}$ and volumetric ethanol productivity of $0.30 \pm 0.01 \mathrm{~g} / \mathrm{L} / \mathrm{h}$. Results obtained in the current study suggest the feasibility of scaling up of production of ethanol from lignocellulosic acid hydrolysate of Prosopis juliflora for second-generation ethanol production co-culture of Pichia stipitis and Saccharomyces cerevisiae (VS3).

\section{Acknowledgements}

We thank the Department of Biotechnology (DBT), Ministry of Science and Technology, UGCMANF and DRS-I SAP (Government of India) for the financial assistance.

\section{References}

[1] Anish, R., and Rao, M. (2009). Bioethanol from lignocellulosic biomass part III hydrolysis and fermentation, In A. Pandey (Eds.), Handbook of Plant-Based Biofuels (pp. 159173). USA: CRC Press, Portland.

[2] Balat, M., \& Balat, H. (2009). Recent trends in global production and utilization of bioethanol fuel. Applied Energy, 86, 2273-2282.

[3] Carvalho, G., Mussatto, S. I., Cândido, E. J., \& Almeida e Silva, J. B. (2006). Comparison of different procedures for the detoxification of eucalyptus hemicellulosic hydrolysate for use in fermentative processes. Journal of Chemical Technology and Biotechnology, 81, 152-157.

[4] Chandel, A. K., da Silva, S. S., \& Singh, O. V. (2011a). Detoxification of lignocellulosic hydrolysates for improved bioethanol production. In M. A. S. Bernardes, (Ed.), Biofuel production-Recent developments and prospects (pp. 225-246). Croatia. In Tech, Rijeka.

[5] Chandel, A. K., Singh, O. V., Narasu, M. L., \& Rao, L. V. (2011b). Bioconversion of Saccharum spontaneum (wild sugarcane) hemicellulosic hydrolysate into ethanol by mono and co-cultures of Pichia stipitis NCIM 3498 and thermotolerant Saccharomyces cerevisiae-VS3. New Biotechnology, 28, 593-599. 
[6] Chandel, A. K., Kapoor, R. K., Singh, A., \& Kuhad, R. C. (2007). Detoxification of sugarcane bagasse hydrolysate improves ethanol production by Candida shehatae NCIM 3501. Bioresource Technology, 98, 1947-1950.

[7] David, T.W. 1994. Determination of ethanol concentration in biomass to ethanol fermentation supernatants by gas chromatography. NREL, LAP-011.

[8] Dehkhoda, A., \& Brandberg, T. (2008). Comparison of vacuum and high pressure evaporated wood hydrolyzate for ethanol production by repeated fed-batch using flocculating Saccharomyces cerevisiae. Bioresources, 4, 309-320.

[9] Gupta, R., Sharma, K. K., \& Kuhad, R. C. (2009). Separate hydrolysis and fermentation (SHF) of Prosopis juliflora, a woody substrate, for the production of cellulosic ethanol by Saccharomyces cerevisiae and Pichia stipitis-NCIM 3498. Bioresource Technology, 100, 1214-1220.

[10] Hahn-Hagerdal, B., Karhumaa, K., Fonseca, C., Spencer-Martins, I., \& Gorwa-Grauslund, M. F. (2007). Towards industrial pentose-fermenting yeast strains. Applied Microbiology and Biotechnology, 74, 937-953.

[11] Hector, R. E., Mertens, J. A., Bowman, M. J., Nichols, N. N., Cotta, M. A., \& Hughes, S. R. (2011). Saccharomyces cerevisiae engineered for xylose metabolism requires gluconeogenesis and the oxidative branch of the pentose phosphate pathway for aerobic xylose assimilation. Yeast (Chichester, England), 28, 645-660.

[12] Hickert, L. R., da Cunha-Pereira, F., de Souza-Cruz, P. B., Rosa, C. A., \& Ayub, M. A. (2013). Ethanogenic fermentation of co-cultures of Candida shehatae HM 52.2 and Saccharomyces cerevisiae ICV D254 in synthetic medium and rice hull hydrolysate. Bioresource Technology, 131, 508-514

[13] Jun-jun, Z., Qiang, Y., Yong, X., \& Shi-yuan, Y. (2009, 16-18 Oct. 2009). Comparative Detoxification of Vacuum Evaporation/Steam Stripping Combined with Overliming on Corn Stover Prehydrolyzate. Paper presented at the Energy and Environment Technology, 2009. ICEET 2009. International Conference, vol. 3, pp. 240-243

[14] Kiran Sree, N., Sridhar, M., Suresh, K., Banat, I. M., \& Venkateswar Rao, L. (2000). Isolation of thermotolerant, osmotolerant, flocculating Saccharomyces cerevisiae for ethanol production. Bioresource Technology, 72, 43-46. 
[15] Krishnan, C., Sousa, L. d. C., Jin, M., Chang, L., Dale, B. E., \& Balan, V. (2010). Alkali-based AFEX pretreatment for the conversion of sugarcane bagasse and cane leaf residues to ethanol. Biotechnology and Bioengineering, 107, 441-450.

[16] Lin, Y., \& Tanaka, S. (2006). Ethanol fermentation from biomass resources: current state and prospects. Applied Microbiology and Biotechnology, 69, 627-642.

[17] Martinez, A., Rodriguez, M. E., York, S. W., Preston, J. F., Ingram, L, O. (2000). Effects of $\mathrm{Ca}(\mathrm{OH})_{2}$ treatments ("overliming") on the composition and toxicity of baggasse hemicellulose hydrolysate. Biotechnology and Bioengineering, 69, 526-536.

[18] Miller, G. L. (1959). Use of dinitro salicylic acid reagent for for determination of reducimg sugar, Analytical Chemistry, 31, 426.

[19] Naseeruddin, S., Desai, S., \& Venkateswar Rao, L. (2017). Ethanol production from lignocellulosic substrate Prosopis juliflora, Renewable Energy, 103 , 701-707

[20] Naseeruddin, S., Srilekha Yadav, K., Sateesh, L., Manikyam, A., Desai, S., \& Venkateswar Rao, L. (2013). Selection of the best chemical pretreatment for lignocellulosic substrate Prosopis juliflora. Bioresource Technologly, 136, 542-549.

[21] Oleskowicz, P. P., Thomsen, A. B, Schmidt, E. J. (2011). Ensiling Wet-storage method for lignocellulosic biomass for bioethanol production. Biomass and Bioenergy, 35, 20872092.

[22] Pasha, C., Thabit, H. M., Kuhad, R. C., \& Linga, V. R. (2008). Bioethanol production from Prosopis juliflora using thermotolerant Saccharomyces cereviseae (VS3) strain. Journal of Biobased Materials and Bioenergy, 2, 204-209.

[23] Pasha, C., Kuhad, R. C., \& Linga, V. R. (2007). Strain improvement of thermotolerant Saccharomyces cereviseae (VS3) strain for better utilization of lignocellulosic substrates. Journal of Applied Microbiology, 103, 1480-1489.

[24] Rilov, G., \& Crooks, J. A. (2008). Biological invasions in marine ecosystems: ecological, management, and geographic perspectives (Vol. 204): Springer. Verlag Berlin Heidelberg, Germany.

[25] Romani, A., Garrote, G., Ballesteros, I., \& Ballesteros, M. (2013). Second generation bioethanol from steam exploded Eucalyptus globulus wood. Fuel, 111, 66-74. 
[26] Singleton, V. L., Rossi, J. A. 1965. Colorimetry of total phenolics with phosphomolybdicphosphotungstic acid reagents. American Journal of Enology and Viticulture, 16, 144158.

[27] Sornvoraweat, Buddhiporn, Jirasak, Kongkiattikajorn, 2009. Dilute Acid Hydrolysis, Enzymatic Saccharification and Fermentation of Water Hyacinth to Ethanol. In: Pure and Applied chemistry International Conference (PACCON 2009), Naresuan University, Thailand

[28] Srilekha Yadav, K., Naseeruddin, S., Sai Prashanthi, G., Sateesh, L., \& Venkateswar Rao, L. (2011). Bioethanol fermentation of concentrated rice straw hydrolysate using coculture of Saccharomyces cerevisiae and Pichia stipitis. Bioresource Technology, 102, 6473-6478. 


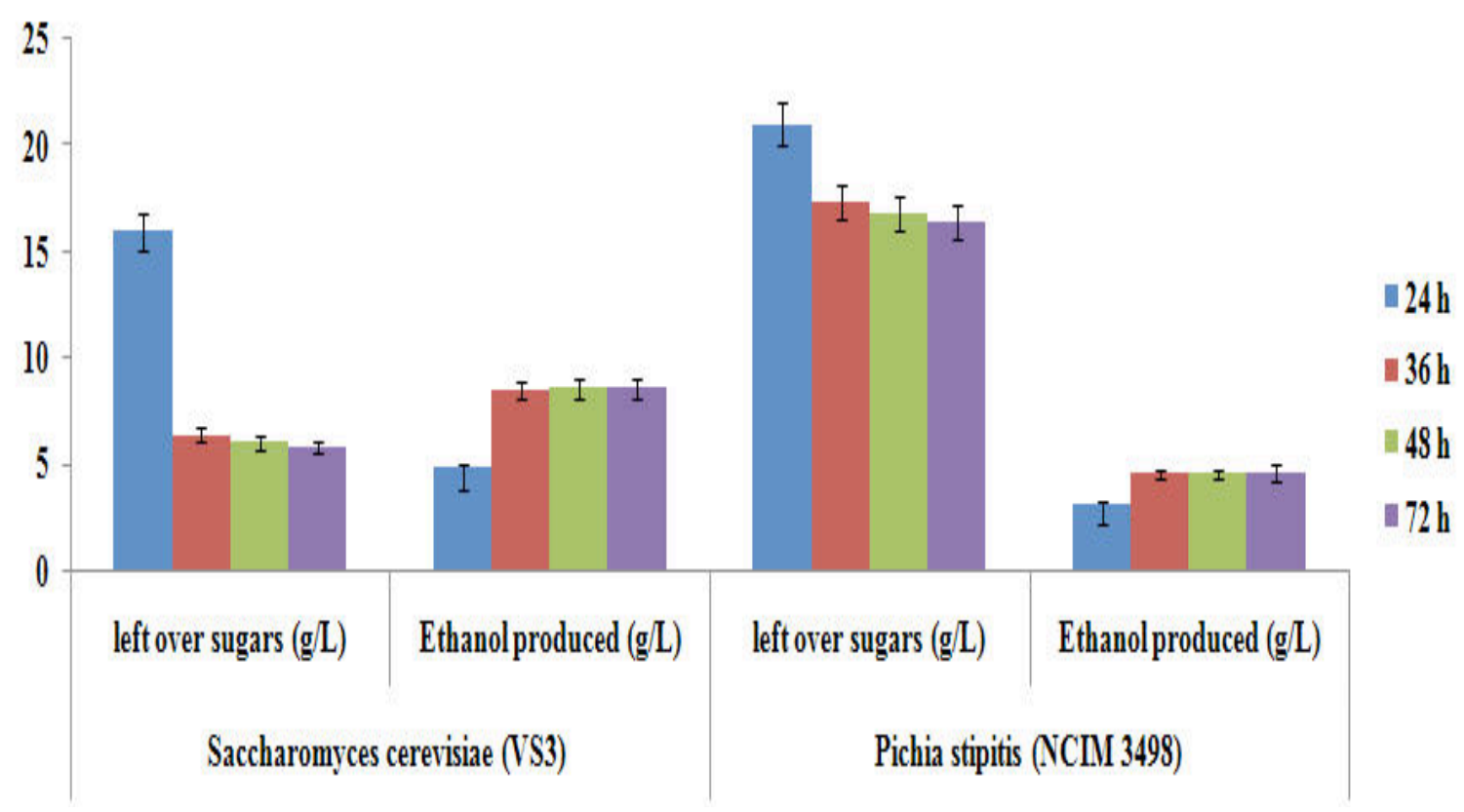

Fig. 1: Fermentation of concentrated and detoxified acid hydrolysate (100g level) with two yeast strains

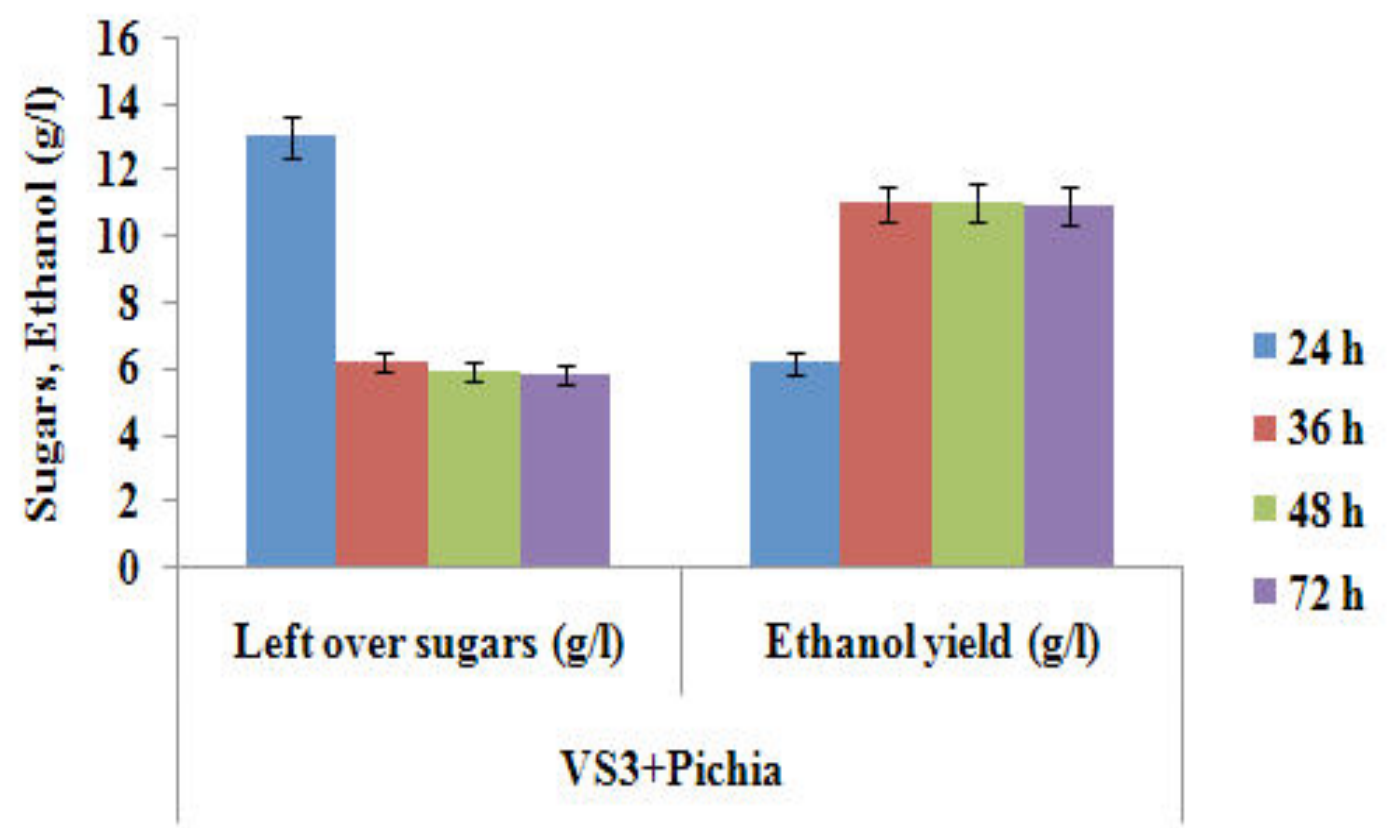

Fig. 2: Fermentation of Prosopis juliflora concentrated and detoxified acid hydrolysate (100g level) with co culture of VS3+Pichia 